\title{
Article \\ A Disintegrin and Metalloprotease 12 Promotes Tumor Progression by Inhibiting Apoptosis in Human Colorectal Cancer
}

\author{
Young-Lan Park, Sun-Young Park, Hyung-Hoon Oh, Min-Woo Chung (D, Ji-Yun Hong, Ki-Hyun Kim, \\ Dae-Seong Myung, Sung-Bum Cho, Wan-Sik Lee, Hyun-Soo Kim and Young-Eun Joo *D
}

Citation: Park, Y.-L.; Park, S.-Y.; Oh, H.-H.; Chung, M.-W.; Hong, J.-Y.; Kim, K.-H.; Myung, D.-S.; Cho, S.-B.; Lee, W.-S.; Kim, H.-S.; et al. A Disintegrin and Metalloprotease 12 Promotes Tumor Progression by Inhibiting Apoptosis in Human Colorectal Cancer. Cancers 2021, 13, 1927. https://doi.org/10.3390/ cancers13081927

Academic Editors: Lisardo Bosca and Éric Chastre

Received: 17 March 2021

Accepted: 12 April 2021

Published: 16 April 2021

Publisher's Note: MDPI stays neutral with regard to jurisdictional claims in published maps and institutional affiliations.

Copyright: (c) 2021 by the authors. Licensee MDPI, Basel, Switzerland. This article is an open access article distributed under the terms and conditions of the Creative Commons Attribution (CC BY) license (https:/ / creativecommons.org/licenses/by/ $4.0 /)$.
Department of Internal Medicine, Chonnam National University Medical School, Gwangju 61469, Korea; kokodeak@hanmail.net (Y.-L.P.); sunfrog@hanmail.net (S.-Y.P.); hyung1125@naver.com (H.-H.O.); zeinf@hanmail.net (M.-W.C.); hongjymd@gmail.com (J.-Y.H.); forestinmind@hanmail.net (K.-H.K.); myungdaeseong@hanmail.net (D.-S.M.); eunabumi@chonnam.ac.kr (S.-B.C.); iliad@chonnam.ac.kr (W.-S.L.); dshskim@chonnam.ac.kr (H.-S.K.)

* Correspondence: yejoo@chonnam.ac.kr; Tel.: +82-62-220-6296; Fax: +82-62-225-8578

Simple Summary: A disintegrin and metalloprotease 12 (ADAM12) has been associated with tumor development and progression. The aim of the current study was to evaluate the impact of ADAM12 on cancer progression, prognosis, and therapeutic targets in colorectal cancer (CRC). Our results show that ADAM12 overexpression enhanced proliferation, inhibited apoptosis, and acted as a positive regulator of cell cycle progression in CRC cells. Phosphorylation of phosphatase and tensin homolog deleted on chromosome 10 (PTEN) was decreased and that of Akt was increased by ADAM12 overexpression. These results were reversed upon ADAM12 knockdown. ADAM12 overexpression was significantly associated with the cancer stage, depth of invasion, lymph node metastasis, distant metastasis, and poor survival in CRC patients. In a mouse xenograft model, tumor area, volume, and weight were significantly greater for the ADAM12 overexpression group and significantly lower for the ADAM12 knockdown group. In conclusion, ADAM12 may serve as a promising biomarker and/or therapeutic target in CRC.

Abstract: A disintegrin and metalloprotease 12 (ADAM12) has been implicated in cell growth, tumor formation, and metastasis. Therefore, we evaluated the role of ADAM12 in colorectal cancer (CRC) progression and prognosis, and elucidated whether targeted downregulation of ADAM12 could lead to therapeutic sensitization. The effect of ADAM12 on tumor cell behavior was assessed in CRC cell lines, CRC tissues, and a mouse xenograft model. ADAM12 overexpression enhanced proliferation, inhibited apoptosis, and acted as positive regulator of cell cycle progression in CRC cells. Phosphorylation of PTEN was decreased and that of Akt was increased by ADAM12 overexpression. These results were reversed upon ADAM12 knockdown. ADAM12 overexpression was significantly associated with the cancer stage, depth of invasion, lymph node metastasis, distant metastasis, and poor survival in CRC patients. In a mouse xenograft model, tumor area, volume, and weight were significantly greater for the ADAM12-pcDNA6-myc-transfected group than for the empty-pcDNA6myc-transfected group, and significantly lower for the ADAM12-pGFP-C-shLenti-transfected group than for the scrambled pGFP-C-shLenti-transfected group. In conclusion, ADAM12 overexpression is essential for the growth and progression of CRC. Furthermore, ADAM12 knockdown reveals potent anti-tumor activity in a mouse xenograft model. Thus, ADAM12 may serve as a promising biomarker and/or therapeutic target in CRC.

Keywords: ADAM12; cell survival; prognosis; colorectal neoplasm

\section{Introduction}

Colorectal cancer (CRC) is one of the major causes of cancer-associated morbidity and mortality worldwide. Despite significant advancements in diagnosis and therapy, fewer 
than $40 \%$ of cases are diagnosed when the cancer is still localized, and the prognosis of advanced CRC remains poor, with progressive behaviors, including cancer invasion and metastasis, being the major contributors to CRC-related morbidity and mortality [1-3]. This highlights the need to develop biomarkers to identify which persons will benefit the most from cancer surveillance and management. Identifying biomarkers that can detect CRC early or monitor cancer progression enables us to personalize medicine and improve the survival rates of patients with cancer $[4,5]$.

A disintegrin and metalloproteases (ADAMs) are members of the membrane-anchored metzincin superfamily of zinc-based metalloproteinases. The mammalian ADAM protein family consists of 40 members, according to current research, and contains a metalloproteinase and disintegrin domain that combines proteolytic and adhesive functions [6,7]. This family is involved in various physiological and pathological processes, including cellular development, modulation of inflammatory reactions, and formation and progression of cancer via the release of membrane-bound proteins, such as adhesion molecules, cytokines, chemokines, and growth factors [8-10].

The human ADAM12 gene is located at 10q26.3 and has a typical ADAM family structure sequence, including metalloproteinase, disintegrin, cysteine-rich, and epidermal growth factor-like domains. ADAM12 is predominantly expressed in certain tissues, including bone, cartilage, brain, liver, heart, and muscle. ADAM12 is a proteolytic member of the ADAM protein family whose functions have been implicated in fertilization, cell adhesion, fusion, migration, proteolysis of extracellular matrix, and cell signaling [11,12]. Recently, ADAM12 has been reported to be highly expressed in various human cancers, including breast, bladder, and lung cancers, and has been associated with tumor development and progression [13-24]. ADAM12 has also been shown to regulate tumor progression in mouse tumor models, either by enhancing resistance to tumor cell apoptosis, by increasing tumor cell proliferation and invasion, or by promoting epithelial-to-mesenchymal transition [25]. In addition, ADAM12 regulates a variety of cellular processes in cancers via multiple signaling transduction pathways, including Akt [11,12]. Previous studies have shown upregulation of ADAM12 in CRC, but its clinical and functional relevance has not been explored [26-28].

The aims of the current study were to evaluate the role of ADAM12 in human CRC progression and prognosis and to elucidate whether targeted downregulation of ADAM12 could lead to therapeutic sensitization using an in vivo mouse xenograft model.

\section{Results}

\subsection{Expression of ADAM12 in Human CRC Cells}

To investigate the expression of ADAM12 in CRC cells, ADAM12 protein expression was examined using Western blotting with ADAM12 and Myc-tagging antibodies in human CRC cell lines DLD1 and SW480. ADAM12 expression was not observed in DLD1 and SW480 cells. Therefore, we experimented with transfecting the ADAM12 gene and knocking it out in DLD1 and SW480 cells. ADAM12-pcDNA6-myc construct or ADAM12 siRNA was used to transfect the ADAM12 gene and knock it out in DLD1 and SW480 cells. ADAM12 protein expression in tested cells showed a significant increase at the protein level by the transfection of ADAM12-pcDNA6-myc construct and a significant decrease by the transfection of ADAM12 siRNA (Figure 1A and Figure S1).

\subsection{Effect of ADAM12 on Proliferation of Human CRC Cells}

To determine the potential effects of ADAM12 on cell proliferation, cells were subjected to a cell proliferation assay two days after transfection with ADAM12-pcDNA6-myc construct or ADAM12 siRNA. The number of proliferating cells, determined by measuring the absorbance of cell suspension, significantly increased to a greater extent in the ADAM12-pcDNA6-myc-transfected DLD1 and SW480 cells than in the empty-pcDNA6myc-transfected cells ( $p<0.05$ and $p<0.05$, respectively). In contrast, ADAM12 siRNAtransfected DLD1 and SW480 cells showed significantly lower proliferation compared to 
scrambled siRNA-transfected cells ( $p<0.05$ and $p<0.05$, respectively; Figure 1B). Plate colony formation assay showed significantly increased cell proliferation due to ADAM12 overexpression ( $p<0.05$ and $p<0.05$, respectively) and decreased cell proliferation due to ADAM12 knockdown ( $p<0.05$ and $p<0.05$, respectively; Figure 1C). Additionally, the bromodeoxyuridine (BrdU) incorporation of proliferating cells was significantly increased in the ADAM12-pcDNA6-myc-transfected DLD1 and SW480 cells compared to the empty-pcDNA6-myc-transfected cells $(p<0.05$ and $p<0.05$, respectively). In contrast, ADAM12 siRNA-transfected DLD1 and SW480 cells showed significantly reduced proliferation compared to scrambled siRNA-transfected cells $(p<0.05$ and $p<0.05$, respectively; Figure 1D).

A

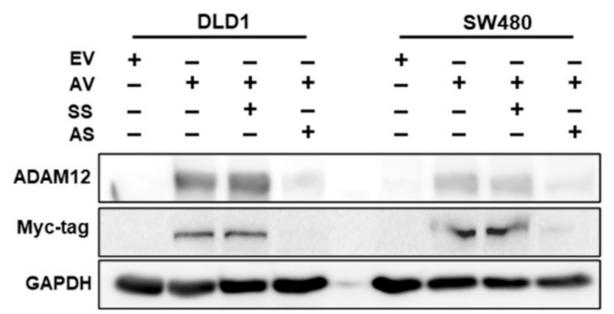

C
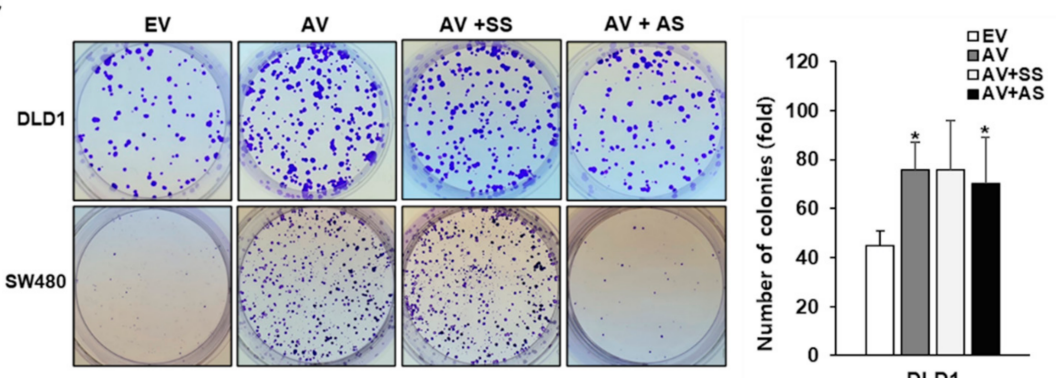

DLD1

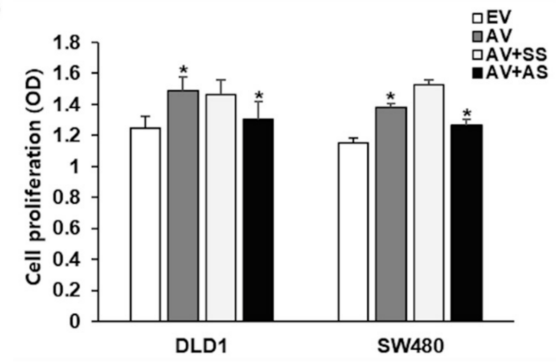

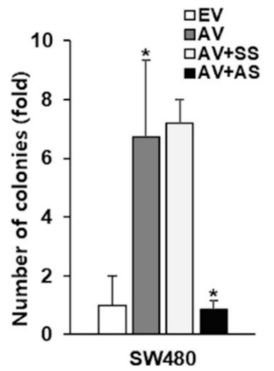

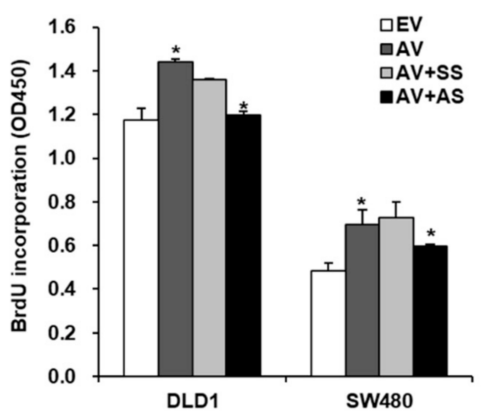

Figure 1. Effect of ADAM12 expression on cell proliferation of human CRC cells. (A) Expression of ADAM12 protein via gene transfection. Western blotting results revealed that ADAM12 protein was overexpressed and knocked down using ADAM12-pcDNA6-myc construct and ADAM12 siRNA, respectively. (B) Effect of ADAM12 expression on proliferation was determined using WST1 assay in human CRC cells $\left({ }^{*} p<0.05\right)$. (C) Plate colony formation assay confirmed single-cell proliferative capability due to ADAM12 expression $\left({ }^{*} p<0.05\right)$. (D) Effect of ADAM12 expression on BrdU incorporation of proliferating human CRC cells $(* p<0.05)$. ADAM12, A disintegrin and metalloprotease 12; CRC, colorectal cancer; EV, EmptyV, empty-pcDNA6-myc vector; AV, ADAM12pcDNA6-myc construct; SS, scramble siRNA; AS, ADAM12 siRNA; BrdU, bromodeoxyuridine.

\subsection{Effect of ADAM12 on Apoptosis and Cell Cycle Progression in Human CRC Cells}

To evaluate the effect of ADAM12 on apoptosis and cell cycle progression, we performed flow cytometric analysis. The cell apoptotic rate induced by the transfection of ADAM12-pcDNA6-myc construct and ADAM12 siRNA significantly increased to a greater 
extent compared with the transfection of ADAM12-pcDNA6-myc construct and scrambled siRNA ( $p<0.05$ and $p<0.05$, respectively) in DLD1 and SW480 cells (Figure 2A,B). To determine the activation of caspases during overexpression and knockdown of ADAM12, we further investigated caspase-specific activities. The expression of cleaved caspase-3, caspase-7, and poly (ADP-ribose) polymerase (PARP) was downregulated after overexpression and upregulated after knockdown of ADAM12 in DLD1 and SW480 cells (Figure 2C and Figure S2).

A

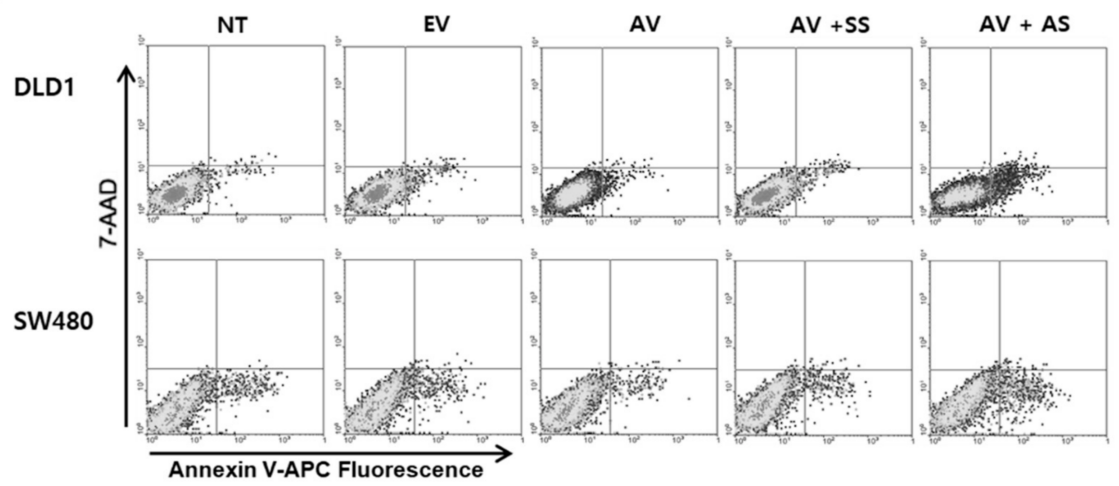

B

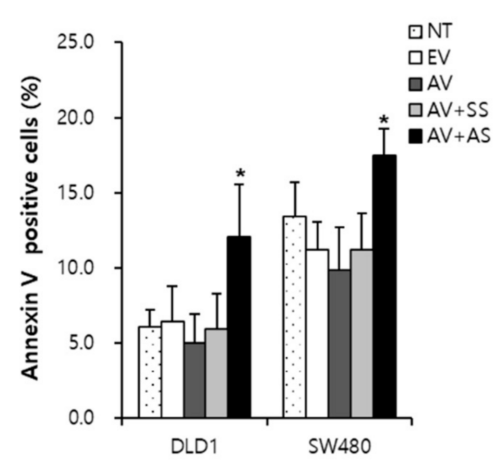

C

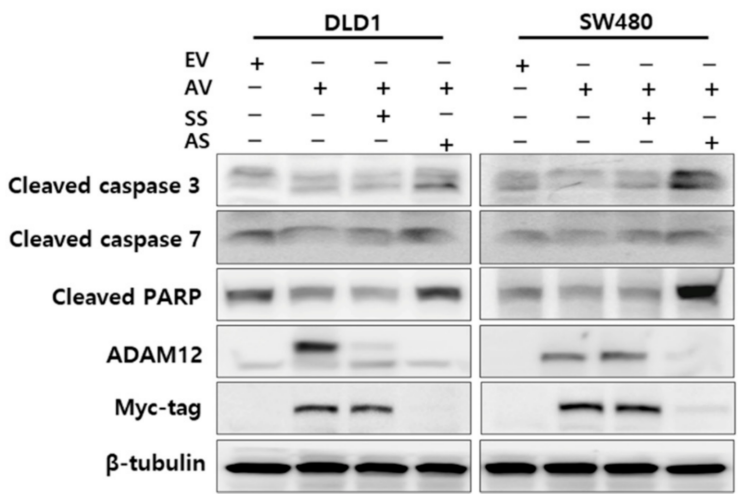

Figure 2. Effect of ADAM12 on apoptosis of human CRC cells. (A) Representative flow cytometry plots. (B) Cell apoptotic rate according to ADAM12 expression was analyzed using Annexin V-APC staining and a FACS Calibur flow cytometer. Bars represent mean \pm standard deviation from three experiments $(* p<0.05)$. (C) Effect of apoptotic proteins according to ADAM12 expression was demonstrated using Western blotting and human CRC cells. Expression of cleaved caspase-3 and -7 and PARP was increased upon ADAM12 knockdown. ADAM12, A disintegrin and metalloprotease 12; CRC, colorectal cancer; NT, non-transfected cells; EV, EmptyV, empty-pcDNA6-myc vector; AV, ADAM12-pcDNA6-myc construct; SS, scramble siRNA; AS, ADAM12 siRNA; PARP, poly (ADPribose) polymerase.

Overexpression of ADAM12 decreased the apoptotic fraction (sub-G1 phase) and knockdown of ADAM12 promoted the apoptotic fraction of DLD1 and SW480 cells (Figure 3A). Next, we evaluated the effects of ADAM12 on cyclins, cyclin-dependent kinases (CDKs), and CDK inhibitors involved in cell cycle progression. As shown in Figure 3B, cyclin D1 and CDK6 protein levels were increased by ADAM12 overexpression in DLD1 and SW480 cells. In contrast, cyclin D1 and CDK6 protein levels were decreased in response to ADAM12 knockdown. p21 and p27 protein levels were decreased by ADAM12 overexpression in DLD1 and SW480 cells. In contrast, p21 and p27 protein levels were increased in response to ADAM12 knockdown (Figure 3B and Figure S3). 
A

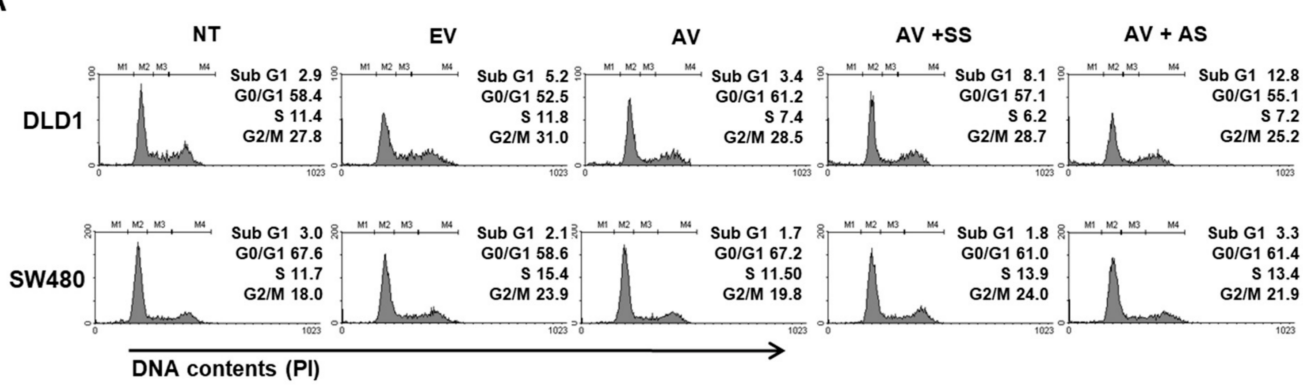

B

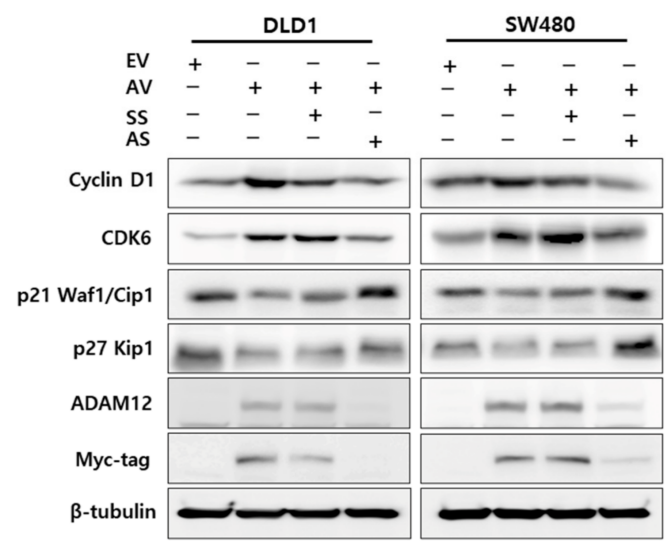

Figure 3. Effect of ADAM12 on cell cycle arrest in human CRC cells. (A) Transfected cells were stained with propidium iodide (PI), then cell cycle distribution by ADAM12 expression was analyzed using a FACS Calibur flow cytometer. (B) Effect of cell cycle-associated proteins based on ADAM12 expression was demonstrated using Western blotting. Cyclin D1 and CDK6 protein levels were increased by ADAM12 overexpression but decreased by ADAM12 knockdown. p21 Kip1 and p27 Waf1/Cip1 protein levels were reduced due to ADAM12 overexpression but increased by ADAM12 knockdown. ADAM12, A disintegrin and metalloprotease 12; CRC, colorectal cancer; NT, nontransfected cells; EV, EmptyV, empty-pcDNA6-myc vector; AV, ADAM12-pcDNA6-myc construct; SS, scramble siRNA; AS, ADAM12 siRNA; CDK6, cyclin-dependent kinase 6.

\subsection{Effect of ADAM12 on Oncogenic Signaling Pathways in Human CRC Cells}

To examine whether ADAM12 activates the intracellular signaling pathways in human CRC cells, we determined the phosphorylation levels of Akt and phosphatase and tensin homolog deleted on chromosome 10 (PTEN) signaling proteins using Western blotting. We found that the phosphorylation of PTEN was decreased and the Akt level was increased due to the overexpression of ADAM12 in DLD1 and SW480 cells. In contrast, the phosphorylation of PTEN was increased and that of Akt was decreased by the knockdown of ADAM12 (Figure 4 and Figure S4).

\subsection{Expression of ADAM12 in Human CRC Tissues}

We evaluated ADAM12 expression at the mRNA and protein level using RT-PCR and immunohistochemistry in human CRC tissues and in normal colorectal mucosal tissue counterparts from the same patients, collected using colonoscopic biopsy and surgical specimens. In the colonoscopic biopsy specimens, we confirmed the upregulation of ADAM12 expression to higher levels in human CRC tissues than in normal mucosa counterparts at the mRNA level (Figure 5A). In paraffin tissue sections, immunostaining of ADAM12 protein was predominantly identified in the cytoplasm of cancer cells and was not detectable in the tumor stroma. Immunostaining showed that ADAM12 protein was not stained or weakly stained in the normal colorectal mucosa (Figure 5B). 


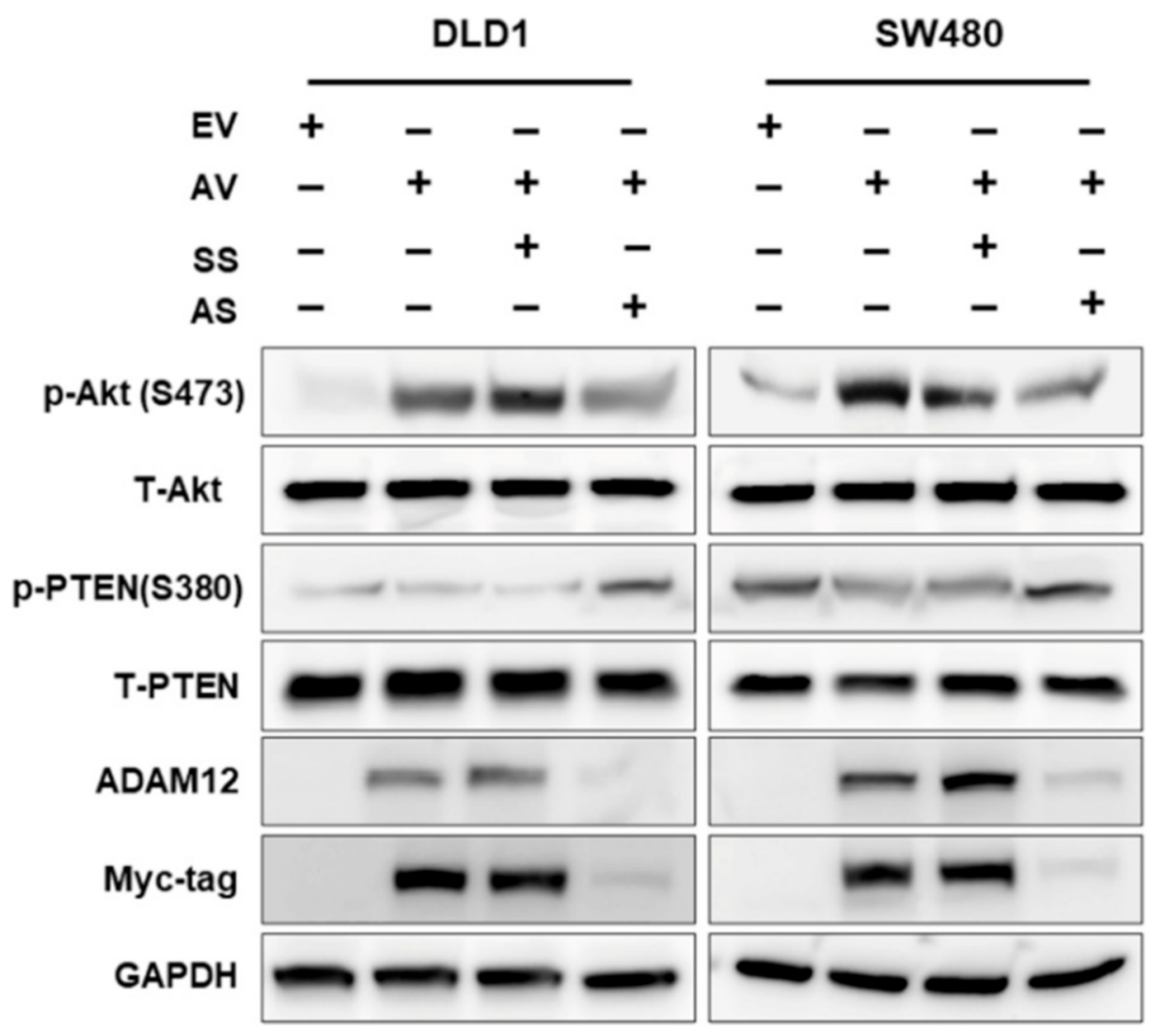

Figure 4. Effect of ADAM12 on oncogenic signaling pathways in human CRC cells. Western blotting demonstrated that phosphorylation of PTEN decreased and Akt level increased upon ADAM12 overexpression; opposite results were observed upon ADAM12 knockdown. ADAM12, A disintegrin and metalloprotease 12; CRC, colorectal cancer; PTEN, phosphatase and tensin homolog deleted on chromosome 10; EV, EmptyV, empty-pcDNA6-myc vector; AV, ADAM12-pcDNA6-myc construct; SS, scramble siRNA; AS, ADAM12 siRNA.

\subsection{Association of ADAM12 with Clinicopathological Variables of Human CRC}

To study the prognostic role of ADAM12 in human CRC progression, we immunohistochemically investigated the expression of ADAM12 protein in formalin-fixed, paraffinembedded tissue blocks obtained from 366 CRC patients. The correlation between ADAM12 immunostaining results and the clinicopathological parameters of patients was analyzed. We observed that ADAM12 expression was significantly associated with cancer stage, depth of invasion, lymph node metastasis, and distant metastasis $(p<0.001, p=0.026$, $p=0.003$, and $p<0.001$, respectively; Table 1). Moreover, the overall survival of patients with ADAM12-positive tumors was significantly lower than that of patients with ADAM12-negative tumors $(p=0.001)$ (Figure 6).

\subsection{Correlation between ADAM12 Protein Expression and Tumor Cell Survival in Human CRC}

All tumor samples underwent terminal deoxynucleotidyl transferase-mediated dUTP nick-end labeling (TUNEL) assay and immunostaining for Ki-67 to identify tumor cell survival. The apoptotic index (AI) of the 366 tumors ranged from 0.6 to 30.0, with a mean of $8.8 \pm 5.6$. The mean AI value of ADAM12-positive tumors was $6.4 \pm 3.7$, which was significantly lower than that of ADAM12-negative tumors $(p=0.009)$. The Ki-67 labeling index (KI) of the 366 tumors ranged from 21.9 to 59.7 with a mean of $52.8 \pm 15.1$. There was no significant difference between ADAM expression and KI results ( $p=0.504$; Table 2). 
A

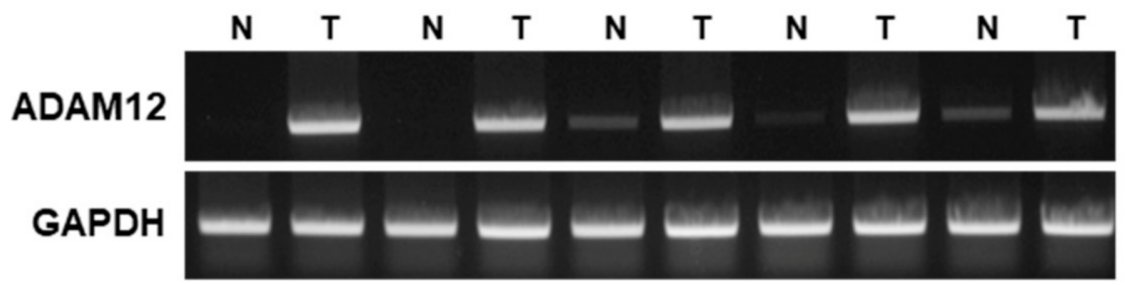

B
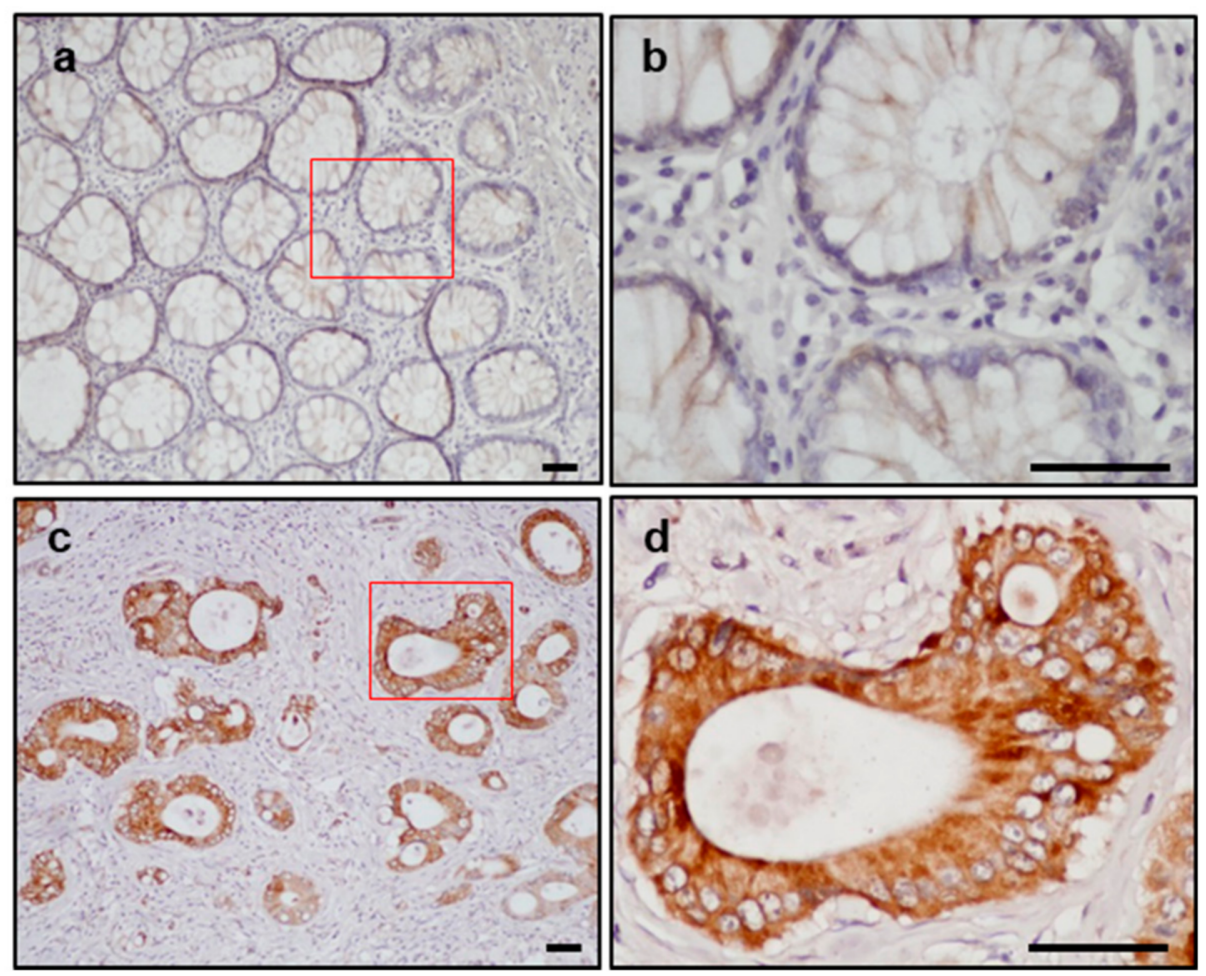

Figure 5. Expression of ADAM12 in human CRC tissues. (A) High expression of ADAM12 mRNA in CRC biopsy tissue was confirmed using RT-PCR. (B) High expression of ADAM12 protein in CRC tissue was confirmed using immunohistochemistry. a: normal colon mucosa; b: red square in a; c: CRC tissue; and d: red square in c. Scale bar $=10 \mu \mathrm{m}$. ADAM12, A disintegrin and metalloprotease 12; GAPDH, glyceraldehyde 3-phosphate dehydrogenase; CRC, colorectal cancer; N, normal colon mucosa; T, CRC tissue. ADAM12 immunoreactivity is predominantly identified in cytoplasm of tumor cells.

\subsection{Effect of ADAM12 on Tumorigenesis of Human CRC Cells in In Vivo Mouse Xenograft Model}

Given our in vitro and human clinical outcome data, we tested the role of ADAM12 in tumor initiation and proliferation in human CRC SW480 cells in vivo, by injecting the same number of empty-pcDNA6-myc vector, ADAM12-pcDNA6-myc construct, scrambled pGFP-C-shLenti, or ADAM12-pGFP-C-shLenti-transfected SW480 cells into non-obese diabetic/severe combined immunodeficiency (NOD/SCID) mice. After 37 days, the tumor area, volume, and weight of the mice in the ADAM12-pcDNA6-myc-transfected group were significantly greater than those of the mice in the empty-pcDNA6-myc-transfected group (Figure 7A,B). The tumor area, volume, and weight for the ADAM12-pGFP-C-shLentitransfected group were significantly lower compared to the scrambled pGFP-C-shLenti- 
transfected group (Figure 7A,B). Taken together, these results indicate that ADAM12 is essential for the growth and progression of human CRC cells in vivo, as well as in vitro.

Table 1. Correlation between ADAM12 expression and clinicopathological parameters of human colorectal cancer.

\begin{tabular}{|c|c|c|c|c|}
\hline \multirow{3}{*}{ Parameters } & \multicolumn{3}{|c|}{ ADAM12 Expression } & \multirow{3}{*}{$p$-Value } \\
\hline & Total & Negative & Positive & \\
\hline & $(n=366)$ & $(n=201)$ & $(n=165)$ & \\
\hline Age (years) & & & & 0.229 \\
\hline$<61.4$ & 159 & 93 & 66 & \\
\hline$\geq 61.4$ & 207 & 108 & 99 & \\
\hline Sex & & & & 0.079 \\
\hline Male & 220 & 129 & 91 & \\
\hline Female & 146 & 72 & 74 & \\
\hline Tumor size (cm) & & & & 0.733 \\
\hline$<4.9$ & 201 & 112 & 89 & \\
\hline$\geq 4.9$ & 165 & 89 & 76 & \\
\hline Stage & & & & $<0.001$ \\
\hline I & 45 & 12 & 8 & \\
\hline II & 143 & 89 & 54 & \\
\hline III & 163 & 78 & 85 & \\
\hline IV & 15 & 5 & 10 & \\
\hline Lymphovascular invasion & & & & 0.062 \\
\hline Negative & 266 & 154 & 112 & \\
\hline Positive & 100 & 47 & 53 & \\
\hline Perineural invasion & & & & 0.824 \\
\hline Negative & 244 & 135 & 109 & \\
\hline Positive & 122 & 66 & 56 & \\
\hline Histologic type & & & & 0.092 \\
\hline WD & 127 & 66 & 61 & \\
\hline MD & 191 & 103 & 88 & \\
\hline $\mathrm{PD}$ & 30 & 17 & 13 & \\
\hline Mucinous/Signet ring cell & 18 & 15 & 3 & \\
\hline Depth of invasion $(\mathrm{T})$ & & & & 0.026 \\
\hline $\mathrm{T} 1$ & 15 & 12 & 3 & \\
\hline $\mathrm{T} 2$ & 47 & 30 & 17 & \\
\hline T3 & 289 & 154 & 135 & \\
\hline $\mathrm{T} 4$ & 15 & 5 & 10 & \\
\hline Lymph node metastasis $(\mathrm{N})$ & & & & 0.003 \\
\hline NO & 191 & 119 & 72 & \\
\hline N1-3 & 175 & 82 & 93 & \\
\hline Distant metastasis (M) & & & & $<0.001$ \\
\hline M0 & 325 & 189 & 136 & \\
\hline M1 & 41 & 12 & 29 & \\
\hline
\end{tabular}

Table 2. Correlation between ADAM12 expression and tumor cell proliferation or apoptosis in human colorectal cancer.

\begin{tabular}{ccccc}
\hline \multirow{2}{*}{ Indices } & \multirow{2}{*}{ Total $(\boldsymbol{n}=\mathbf{3 6 6})$} & \multicolumn{2}{c}{ ADAM12 Expression } & \multirow{2}{*}{$\boldsymbol{p}$-Value } \\
\cline { 3 - 4 } & & Negative $(\boldsymbol{n = 2 0 1 )}$ & Positive $(\boldsymbol{n = 1 6 5 )}$ & 0.504 \\
KI (mean \pm SD) & $52.8 \pm 15.1$ & $51.1 \pm 14.7$ & $54.3 \pm 15.6$ & 0.009 \\
AI (mean \pm SD) & $8.8 \pm 5.6$ & $11.3 \pm 6.4$ & $6.4 \pm 3.7$ & \\
\hline
\end{tabular}

ADAM12, A disintegrin and metalloprotease12; KI, Ki-67 labeling index; AI, apoptotic index; SD, standard deviation. 


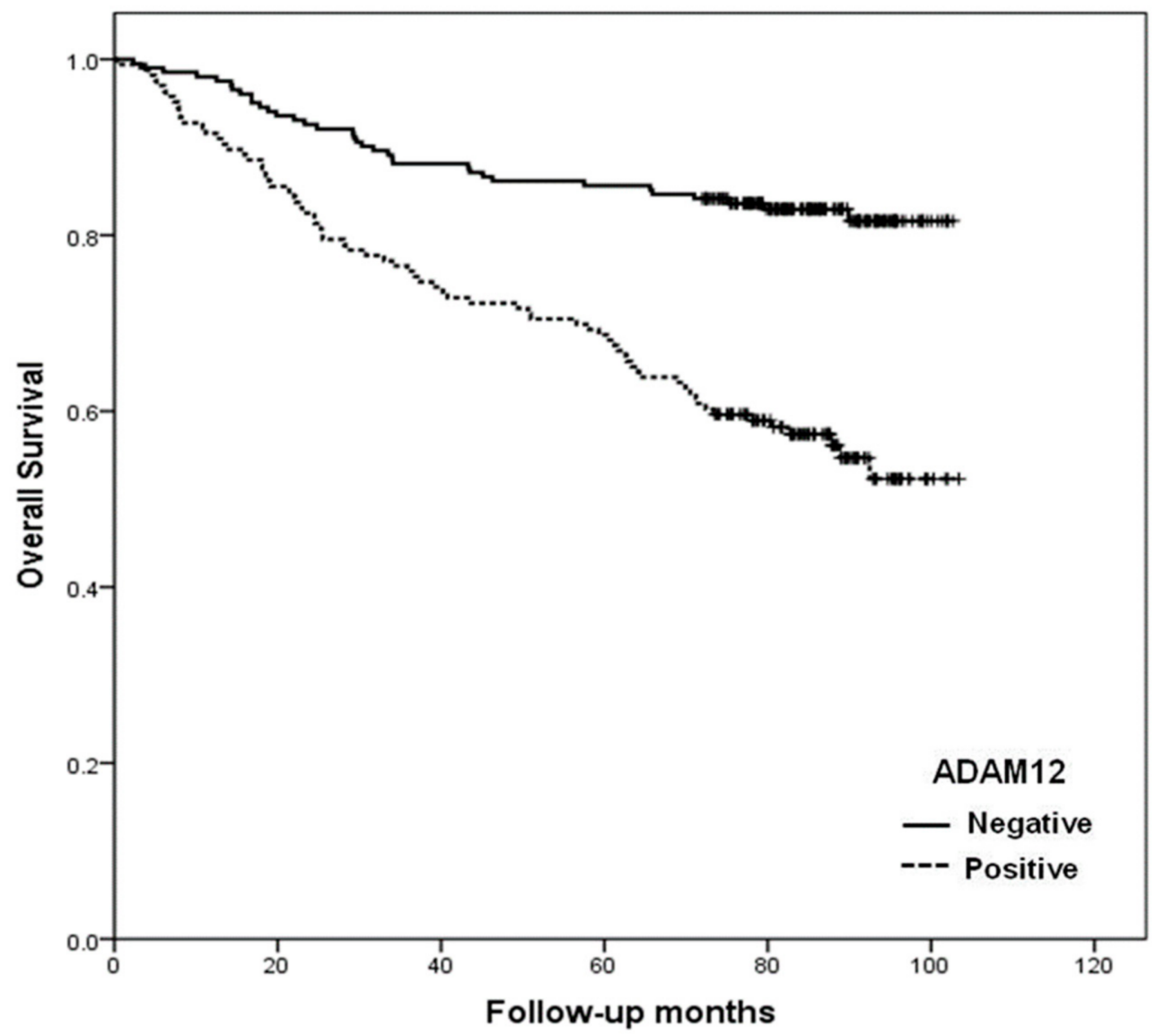

Figure 6. Overall survival curves according to ADAM12 expression in patients with CRC. Positive expression of ADAM12 (dotted line) was associated with poor survival in patients with CRC $(p=0.001)$. ADAM12, A disintegrin and metalloprotease 12; CRC, colorectal cancer.

A

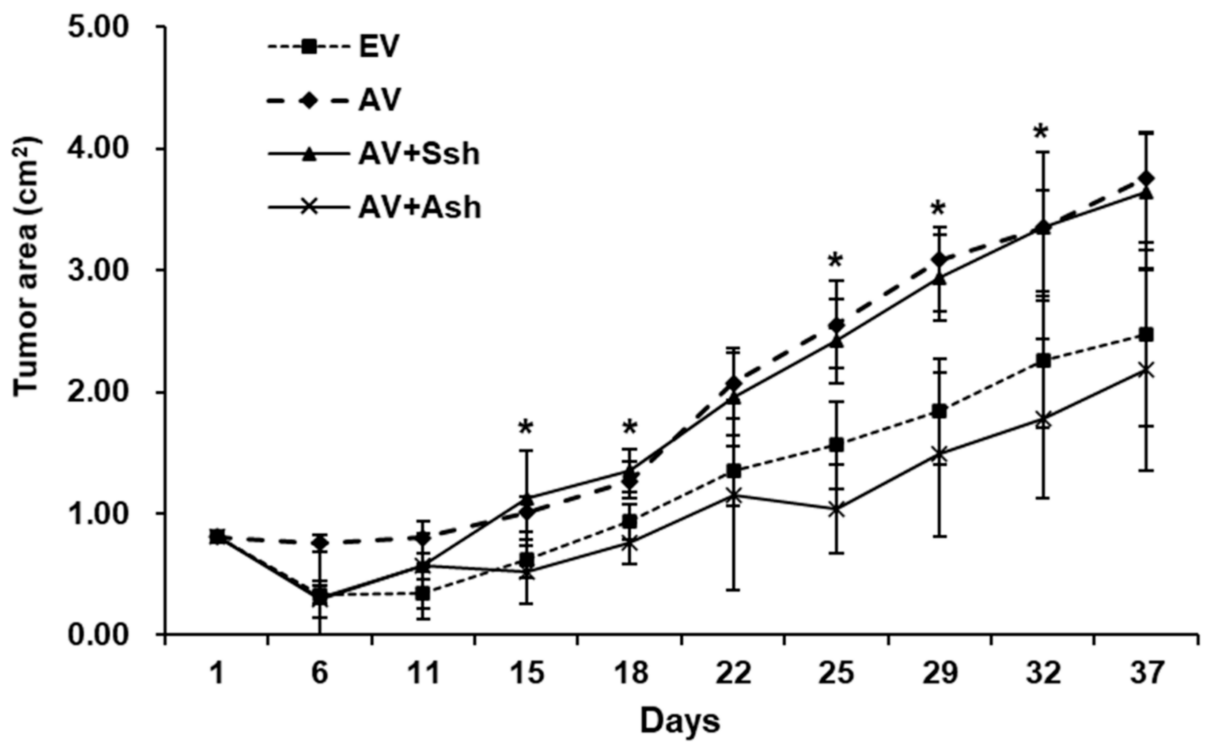

Figure 7. Cont. 
B
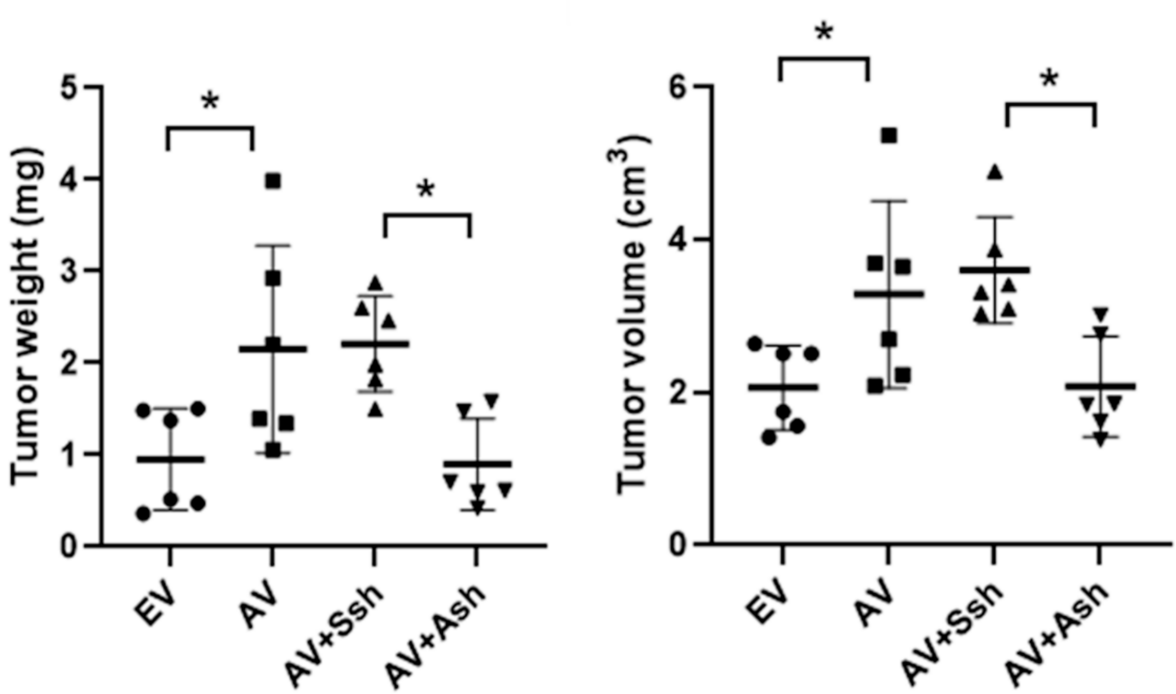

Figure 7. Effect of ADAM12 expression on tumor growth in subcutaneous xenograft model. SW480 cells with stable gene expression of ADAM12 were implanted subcutaneously onto backs of NOD/SCID mice (four groups, $n=6$ ). (A) For 37 days, tumor growth was measured and calculated. (B) Volume and weight of tumor tissue obtained from sacrificed mice 37 days after transplantation were measured and calculated. ADAM12, A disintegrin and metalloprotease 12; NOD/SCID, nonobese diabetic/severe combined immunodeficiency; EV, EmptyV, empty-pcDNA6-myc vector; AV, ADAM12-pcDNA6-myc construct; Ssh, Scrambled pGFP-C-shLenti vector; Ash, ADAM12-pGFP-CshLenti construct. ${ }^{*} p<0.05$.

\section{Discussion}

Altered expression of ADAM12 is implicated in a variety of pathological diseases, such as diabetes, sepsis, rheumatoid arthritis, Alzheimer's disease, atherosclerosis, cardiovascular disease, asthma, and cancer [11,12]. ADAM12 expression is increased in many human cancers, such as breast, bladder, lung, prostate, and liver cancer, and its expression correlates with the tumor stage and prognosis in breast, bladder, and lung cancer [13-22]. However, its role and molecular mechanisms in CRC remain unclear [26-28]. Therefore, we investigated whether ADAM12 may serve as a novel biomarker and/or therapeutic target in CRC, using human CRC cell lines, human CRC tissues, and an in vivo xenograft tumor model.

Proper regulation of cell proliferation, apoptosis, and cell cycle is crucial in order to maintain tissue homeostasis, and its dysregulation is a principal hallmark of cancer cells $[29,30]$. Furthermore, cancer cells are typically characterized by increased proliferation and resistance toward apoptosis and cell cycle control [31,32]. Previously, upregulation of ADAM12 was shown to promote proliferation and inhibit apoptosis of various human cancer cells [13-22]. In our study, overexpression of ADAM12 enhanced proliferation and inhibited apoptosis by downregulating caspase-specific activities, and acted as a positive regulator of cell cycle progression via the upregulation of cyclins and CDKs and the downregulation of CDK inhibitors in human CRC cells. These results were reversed after knockdown of ADAM12. These results suggest that ADAM12 contributes to the alteration of tumor cell survival in human CRC.

To elucidate the underlying mechanisms leading to these results, we analyzed the effect of ADAM12 on the stimulation of multiple intracellular signaling pathways regulating tumor cell survival. The Akt signaling pathway is involved in many cellular programs, such as cell survival and proliferation. Dysregulation of this pathway has been associated with many human diseases, including cancer, highlighting its potential as a therapeutic target for cancer [33]. The tumor suppressor PTEN is involved in the regulation of a variety of pathophysiological processes, such as cell proliferation, adhesion, and apoptosis, through inactivation of focal adhesion kinase and downregulation of the Akt signaling 
pathway [34]. Previously, it was shown that ADAM12 inhibits apoptosis by regulating Akt and mitogen-activated protein kinase signaling pathways in breast and liver cancer cells $[22,35,36]$. Additionally, ADAM12 regulates prostatic cancer cell invasion through the NF- $\mathrm{kB}$ signaling pathway [37]. Consistent with these findings, we found that phosphorylation of PTEN was decreased and Akt was increased by overexpression of ADAM12 in human CRC cells. In contrast, these results were reversed after knockdown of ADAM12. PTEN, a dual protein and lipid phosphatase, dephosphorylates not only proteins, but also phosphatidylinositol-3,4,5-trisphosphate (PIP3), generated by PI3-kinase, thus counteracting the Akt signaling pathway. Thus, loss of PTEN could lead to increased amounts of PIP3, which is a strong activator of the Akt signaling pathway $[33,34]$. These results suggest that ADAM12 participates in altering the oncogenic behavior of human CRC cells by regulating the phosphorylation of Akt and PTEN.

In our study, although ADAM12 expression was not observed in CRC cell lines, ADAM12 expression was upregulated to higher levels in human CRC tissues than in normal mucosa counterparts at the mRNA and protein levels in colonoscopic biopsy and surgical specimens. Overexpression of ADAM12 was significantly associated with the cancer stage, depth of invasion, lymph node metastasis, distant metastasis, and poor survival in patients with CRC. Moreover, we observed that the mean AI value of ADAM12positive tumors was significantly lower than that of ADAM12-negative tumors. These results confirm the resisting apoptotic potential of ADAM12 in vivo, consistent with the results of in vitro studies.

Finally, given our in vitro and human clinical outcome data, we evaluated the effect of ADAM12 on the tumorigenesis of human CRC cells in an in vivo xenograft model with human CRC cells subcutaneously injected into immunocompromised mice. The tumor area, volume, and weight in the ADAM12-pcDNA6-myc-transfected mice were significantly greater than those of the empty-pcDNA6-myc-transfected mice. The tumor area, volume, and weight in the ADAM12-pGFP-C-shLenti-transfected mice were significantly reduced compared to those in the scrambled pGFP-C-shLenti-transfected mice. These results indicate that the ADAM12 status is associated with cancer growth and progression in the in vivo mouse xenograft model.

However, the subcutaneous xenograft model used in our study has limitations: the lack of a direct relation with local invasion and metastases, and the ability to reproduce the tumor/microenvironment interaction. Therefore, orthotopic implantation of human CRC cells into the equivalent colons of live mice is preferred to evaluate the in vivo efficacy of new biomarkers and therapeutic targets in CRC because it provides tumor cells a microenvironment for organotypic interaction [38]. Further study using an orthotopic xenograft model is needed to validate ADAM12 as a biomarker and therapeutic target for CRC.

\section{Materials and Methods}

\subsection{Cell Culture}

Human colorectal cancer (CRC) cell lines (SW480, CCL-228TM and DLD1, CCL221TM) obtained from patients with CRC adenocarcinoma at Dukes stage $B$ and $C$ were purchased from the American Type Culture Collection (Manassas, VA, USA). Cells were cultured in high glucose Dulbecco's modified Eagle's medium (DMEM; Gibco, Thermo Fisher Scientific, Inc., Waltham, MA, USA) supplemented with $10 \%$ fetal bovine serum (Gibco, Thermo Fisher Scientific, Inc.). All cells were maintained at $37^{\circ} \mathrm{C}$ in a humidified atmosphere containing $5 \% \mathrm{CO}_{2}$.

\subsection{Gene Transfection}

The ADAM12-pcDNA6-myc vector was constructed to overexpress the ADAM12 gene in both in vitro and in vivo experiments. To silence the gene, ADAM12 small interfering (si) RNA (GACUACAACGGGAAAGCAA-dTdT) and ADAM12-pGFP-C-shLenti construct were purchased from Bioneer (Daejeon, Korea) and Origene (Rockville, MD, USA), respec- 
tively. Transfection of the vector and siRNAs was performed using Lipofectamine ${ }^{\mathrm{TM}} 2000$ and Lipofectamine ${ }^{\mathrm{TM}}$ RNAiMAX (Invitrogen, Thermo Fisher Scientific, Inc.), according to the manufacturer's instructions. Stable transfectants containing the ADAM12-pcDNA6myc construct and the ADAM12-pGFP-C-shLenti construct were isolated using DMEM with antibiotics $(10 \mu \mathrm{g} / \mathrm{mL}$ blasticidine and $2 \mu \mathrm{g} / \mathrm{mL}$ puromycin, respectively).

\subsection{Cell Proliferation Assay}

Gene-transfected cells were plated onto 96-well culture plates at a density of 5000 cells per well in triplicate. At the indicated time points, $10 \%$ of water-soluble tetrazolium salt reagent (WST-1; EZ-CYTOX, DoGen; Daeillab, Seoul, South Korea) was added. After incubation for an additional $2 \mathrm{~h}$, the optical density (OD) was measured at $450 \mathrm{~nm}$ using an Infinite M200 (Tecan, Mannedorf, Switzerland). All experiments were performed 3 times.

\subsection{Plate Colony Formation Assay}

Cells were seeded in a 6-well plate at a density of 400 cells/well after $24 \mathrm{~h}$ of gene transfection and maintained for 8 days at $37{ }^{\circ} \mathrm{C}$ in humidified $5 \% \mathrm{CO}_{2}$ conditions. Cells were washed with phosphate-buffered saline (PBS) to remove the debris and fixed using $4 \%$ paraformaldehyde for $1 \mathrm{~h}$. The plates were then washed with PBS and stained with a $0.1 \%$ crystal violet solution (Sigma-Aldrich, St. Louis, MO, USA) for $5 \mathrm{~min}$. The number of colonies with diameters larger than $1 \mathrm{~mm}$ was counted after washing.

\subsection{Bromodeoxyuridine (BrdU) Cell Proliferation Assay}

BrdU Cell Proliferation Assay Kit (cell signaling) was used for the BrdU incorporation assay. In brief, cells labeled with BrdU for $24 \mathrm{~h}$ were treated with fixing/denaturing solution, then with mouse anti-BrdU for $1 \mathrm{~h}$. After incubation with horseradish peroxidase (HRP)conjugated antibody, quantified BrdU-labeled cells were added to the tetramethylbenzidine (TMB) substrate and measured using a microplate reader.

\subsection{Reverse-Transcription PCR}

Total RNA was extracted from the biopsy tissues using Trizol reagent (Invitrogen, Carlsbad, CA, USA) and cDNA was reverse transcribed from 500 ng of total RNA using PrimeScript ${ }^{\circledR}$ RT Master Mix (Takara, Japan). The PCR reactions were carried out using specific primers. The following primers were used: human ADAM12 (forward-GCTGATGAAGTTGTCAGTGC, reverse-CATGACAATTCCCCCAGACTG) and housekeeping gene glyceraldehyde 3-phosphate dehydrogenase (GAPDH) (forwardACCACAGTCCATGCCATCAC, reverse-TCCACCACCCTGTTGCTGTA). The reaction products were visualized on $1 \%$ agarose electrophoresis gel using EtBr staining, and the bands were analyzed using Multi Gauge version 3.0 (Fujifilm, Tokyo, Japan).

\subsection{Western Blotting}

The gene-transfected cells were collected, washed with cold PBS, and lysed in radioimmunoprecipitation assay (RIPA) buffer (Thermo Fisher Scientific, Inc.) with Halt ${ }^{\mathrm{TM}}$ Protease and Phosphatase Inhibitor Cocktail (Thermo Fisher Scientific, Inc.). The protein concentration was quantified using $\mathrm{BC} \mathrm{A}^{\mathrm{TM}}$ protein assay (Thermo Fisher Scientific, Inc.). The total cellular lysates were resolved using sodium dodecyl sulfate (SDS)-polyacrylamide gel electrophoresis, subsequently transferred onto a polyvinylidene fluoride (PVDF) membrane (Millipore, Billerica, MA, USA), and separately immunoblotted with specific antibodies at 1:1000 dilution. The following antibodies were used: ADAM12 (Abcam, Cambridge, UK), Myc-tag, cleaved poly (ADP-ribose) polymerase (PARP), cleaved caspase-3, cleaved caspase-7, cyclin D1, p27Kip1, cyclin-dependent kinase 6 (CDK6), p21 Waf1/Cip1, phosphoAkt (S473), Akt, phosphatase and tensin homolog deleted on chromosome 10 (PTEN) (S380), PTEN (Cell Signaling Technology, Inc., Danvers, MA, USA), and GAPDH (Santa Cruz Biotechnology, Inc., Dallas, TX, USA). The membrane was then washed and developed using an enhanced chemiluminescence detection kit (Amersham, GE Healthcare Life Sci- 
ences). The protein bands were visualized using an LAS-4000 luminescent image analyzer (Fujifilm, Tokyo, Japan).

\subsection{Flow Cytometry Determination of Apoptosis}

Cells were washed twice with PBS, then the pellets were resuspended in $1 \times$ Binding Buffer (0.01 M HEPES pH 7.4, $0.14 \mathrm{M} \mathrm{NaCl}$ and $\left.2.5 \mathrm{mM} \mathrm{CaCl}_{2}\right)$. Each sample was transferred to a tube and stained with Annexin V-APC and 7-amino-actinomycin D (7-AAD) (BD Biosciences, San Diego, CA, USA) at room temperature for $20 \mathrm{~min}$. After incubation in the dark at room temperature, $400 \mu \mathrm{L}$ of $1 \times$ Binding Buffer was added and the cell suspensions were analyzed using a FACS Calibur flow cytometer (Becton Dickinson, San Jose, CA, USA) and WinMDI version 2.9 (Scripps Research Institute, Jupiter, FL, USA). Finally, 3 experiments were performed to analyze the rate of cell apoptosis.

\subsection{Flow Cytometry Analysis of Cell Cycle Arrest}

Cells were washed twice with PBS and fixed in ice-cold 70\% ethanol. Fixed cells were incubated in $10 \mu \mathrm{g} / \mathrm{mL}$ ribonuclease A (Sigma-Aldrich, St. Louis, MO, USA) and stained with propidium iodide ( $50 \mathrm{mg} / \mathrm{mL}$, Sigma-Aldrich) at room temperature for $30 \mathrm{~min}$. Cells were subsequently analyzed using a FACS Calibur flow cytometer (Becton Dickinson). The fractions of cells in the sub-G1, G0/G1, S, and G2/M phases were analyzed using WinMDI version 2.9 (Scripps Research Institute Jupiter, FL, USA).

\subsection{Patients and Tissue Samples}

For the RNA preparation, 20 colon cancer tissue samples and normal colon tissue counterparts were collected via colonoscopic biopsy at Chonnam University Hwasun Hospital (Jeonnam, Korea). For immunohistochemistry (IHC), formalin-fixed and paraffinembedded tissue samples were selected from 366 patients who underwent surgery for pathologically confirmed colon cancer at that hospital between January 2004 and December 2006. The primary selection criteria were the availability of formalin-fixed and paraffin-embedded tissue blocks and sufficient clinical follow-up for tumor-specific survival analysis. No patient had received preoperative chemo- or radiotherapy. Tissue blocks were selected by viewing the original pathologic slides and choosing blocks that showed the junction between the normal colon epithelium and the tumor region. Patients were followed up to December 2012, and overall survival (OS) was defined as the interval between surgery and death or the last follow-up. This study was approved by the Institutional Review Board of the Chonnam National University Hwasun Hospital (IRB No. CNUHH-2017-164), and written informed consent was obtained from every patient.

\subsection{Immunohistochemistry (IHC)}

Paraffin sections were deparaffinized and the endogenous peroxidase was neutralized using Peroxidase-Blocking Solution (Dako, Carpinteria, CA, USA). After antigen retrieval was performed in citrate buffer at $\mathrm{pH} 6.0$, the tissues were incubated with the primary anti-ADAM12 (Abcam), Ki-67 (Dakopatts, Glostrup, Denmark). The tissue was then stained using the Dako REAL ${ }^{\mathrm{TM}}$ EnVision HRP/DAB Detection System and counterstained with hematoxylin.

\subsection{Evaluation of ADAM12 Expression}

The ADAM12 IHC score was calculated by multiplying the staining intensity score by the percentage of positive cells. The intensity of ADAM12 immunoreactive intensity was scored as follows: 0 , negative; 1 , weak; 2 , moderate; and 3, strong. The scores for the percentage of positive cells were also divided into 4 grades: $1,0-25 \% ; 2,26-50 \%$; , $51-75 \%$; and $4,>75 \%$ positive cells. The average of the final scores for the 366 tumor samples was presented as a reference point to divide them into 2 subgroups, positive and negative expression. Samples with a final score $>7$ were designated as positive for 
ADAM12 expression. These judgments were made by 2 independent pathologists without knowledge of the patient clinical outcome data.

\subsection{Assessment of Apoptosis and Tumor Cell Proliferation}

Detection of apoptotic tumor cells in the sample tissue was performed using a terminal deoxynucleotidyl transferase-mediated dUTP nick-end labeling (TUNEL) technology system (Promega, Madison, WI, USA), according to the manufacturer's instructions. Briefly, deparaffinized tissues were rehydrated and incubated in a permeabilization solution. Labeling of apoptotic cells was performed by adding terminal deoxynucleotide transferase enzyme (TdT) reaction mix to the tissue sections on the slides. After washing, color development for localization of labeled cells was performed by incubating the slides with the enzyme substrate 3,3-diaminobenzidine (DAB). The apoptotic index (AI) was determined by counting the number of TUNEL positive cells per 1000 tumor cell nuclei. Tumor proliferative cells were detected using $\mathrm{Ki}-67$ antibody by IHC, and the immunostained nuclei were considered as positively labeled. The number of Ki-67 positive nuclei per 1000 tumor cell nuclei was presented as the Ki-67 labeling index (KI).

\subsection{In Vivo Tumor Model Experiment}

The mouse experimental design and protocols used in this study were approved by the Chonnam National University Hwasun Hospital animal care and use committee (CNUIACUC-H-2018-64). Male 6-week-old non-obese diabetic/severe combined immunodeficiency (NOD/SCID) mice were purchased from Charles River Laboratories (Yokohama, Japan) and divided into 4 groups $(n=6)$. Mice were allowed to adapt to the breeding environment for 7 days before the experiment, and were divided into 4 groups (each $n=6$ ) for tumor cell implantation: empty-pcDNA6-myc vector transfected stable cells (EV, group 1), ADAM12-pcDNA 6-myc construct transfected stable cells (AV, group 2), AV and scrambled pGFP-C-shLenti construct double transfected stable cells (AV+Ssh, group 3), and AV and ADAM12-pGFP-C-shLenti construct double transfected stable cells (AV+Ash, group 4). To generate subcutaneous human colon cancer xenografts, $2 \times 10^{6}$ stable cells with ADAM12-pcDNA 6-myc construct or ADAM12-pGFP-C-shLenti construct were suspended in $100 \mu \mathrm{L}$ of serum-free DMEM, and cell suspension was subcutaneously injected into the back of each mouse. Thirty-seven days after tumor cell inoculation, all mice were sacrificed and the subcutaneous tumors were removed. The weight and volume of implanted tumors was calculated, and the tumor tissue was immediately fixed in a $10 \%$ formalin solution, then embedded in paraffin for hematoxylin and eosin (H\&E) staining.

\subsection{Statistical Analysis}

The association between ADAM12 expression and clinicopathological parameters was analyzed using $\chi^{2}$ test and Fisher's exact test with SPSS version 20.0 software (IBM Corporation, Armonk, NY, USA). Kaplan-Meier analysis and log-rank tests were used to perform survival analysis. The associations between experimental groups were determined using ANOVA/Tukey test. A value of $p<0.05$ was considered significant.

\section{Conclusions}

In conclusion, overexpression of ADAM12 contributes to the oncogenic phenotypes of human CRC cells. Moreover, ADAM12 expression is upregulated in human CRC tissues and associated with poor prognosis in patients with CRC. In addition, overexpression of ADAM12 enhanced the growth and progression of human CRC cells, and knockdown of ADAM12 showed potent anti-tumor activity in our in vivo mouse xenograft model. Thus, ADAM12 may serve as a promising biomarker and/or therapeutic target in human CRC.

Supplementary Materials: The following are available online at https:/ / www.mdpi.com/article/10 .3390 / cancers13081927/s1, Figure S1: Expression of ADAM12 protein via gene transfection, Figure S2: Effect of apoptotic proteins according to ADAM12 expression, Figure S3: Effect of cell cycle-associated 
proteins based on ADAM12 expression, Figure S4: Effect of ADAM12 on oncogenic signaling pathways in human CRC cells.

Author Contributions: Conceptualization, Y.-E.J.; formal analysis, H.-H.O., Y.-E.J., D.-S.M., and Y.-L.P.; investigation, Y.-L.P., S.-Y.P., and Y.-E.J.; resources, H.-H.O., M.-W.C., J.-Y.H., K.-H.K., S.-B.C., W.-S.L., and H.-S.K.; data curation, Y.-L.P., S.-Y.P., and Y.-E.J.; writing-original draft preparation, Y.-E.J.; writing-review and editing, H.-H.O. and Y.-E.J.; visualization, Y.-L.P.; supervision, Y.-E.J.; project administration, Y.-E.J.; funding acquisition, Y.-E.J. All authors have read and agreed to the published version of the manuscript.

Funding: This research was supported by a National Research Foundation of Korea (NRF) grant funded by the Korean government (MSIT), grant number NRF-2017R1A2B4004703, and partly by Chonnam National University Hwasun Hospital Institute for Biomedical Science, grant number HCRI20020.

Institutional Review Board Statement: The study was conducted according to the guidelines of the Declaration of Helsinki, and approved by the Institutional Review Board Chonnam National University Hwasun Hospital (IRB No. CNUHH-2017-164).

Informed Consent Statement: Informed consent was obtained from all subjects involved in the study.

Data Availability Statement: Data available in a publicly accessible repository.

Conflicts of Interest: The authors declare no conflict of interest.

\section{References}

1. Mattiuzzi, C.; Sanchis-Gomar, F.; Lippi, G. Concise update on colorectal cancer epidemiology. Ann. Transl. Med. 2019, 7, 609. [CrossRef] [PubMed]

2. Ahmed, M. Colon Cancer: A Clinician's Perspective in 2019. Gastroenterol. Res. 2020, 13, 1-10. [CrossRef] [PubMed]

3. Bevan, R.; Rutter, M.D. Colorectal Cancer Screening-Who, How, and When? Clin. Endosc. 2018, 51, 37-49. [CrossRef] [PubMed]

4. Jung, G.; Hernández-Illán, E.; Moreira, L.; Balaguer, F.; Goel, A. Epigenetics of colorectal cancer: Biomarker and therapeutic potential. Nat. Rev. Gastroenterol. Hepatol. 2020, 17, 111-130. [CrossRef]

5. Oh, H.H.; Joo, Y.E. Novel biomarkers for the diagnosis and prognosis of colorectal cancer. Intest. Res. 2020, 18, 168-183. [CrossRef]

6. Edwards, D.R.; Handsley, M.M.; Pennington, C.J. The ADAM metalloproteinases. Mol. Asp. Med. 2008, 29, 258-289. [CrossRef]

7. Reiss, K.; Saftig, P. The "A disintegrin and Metalloprotease" (ADAM) family of sheddases: Physiological and cellular functions. Semin. Cell Dev. Biol. 2009, 20, 126-137. [CrossRef]

8. Raeeszadeh-Sarmazdeh, M.; Do, L.D.; Hritz, B.G. Metalloproteinases and Their Inhibitors: Potential for the Development of New Therapeutics. Cells 2020, 9, 1313. [CrossRef]

9. Herrera, C.; Escalante, T.; Rucavado, A.; Fox, J.W.; Gutiérrez, J.M. Metalloproteinases in disease: Identification of biomarkers of tissue damage through proteomics. Expert Rev. Proteom. 2018, 15, 967-982. [CrossRef]

10. Zadka, L.; Kulus, M.J.; Piatek, K. ADAM protein family-its role in tumorigenesis, mechanisms of chemoresistance and potential as diagnostic and prognostic factors. Neoplasma 2018, 65, 823-839. [CrossRef]

11. Nyren-Erickson, E.K.; Jones, J.M.; Srivastava, D.K.; Mallik, S. A disintegrin and metalloproteinase-12 (ADAM12): Function, roles in disease progression, and clinical implications. Biochim. Biophys. Acta 2013, 1830, 4445-4455. [CrossRef]

12. Jacobsen, J.; Wewer, U.M. Targeting ADAM12 in human disease: Head, body or tail? Curr. Pharm. Des. 2009, 15, 2300-2310. [CrossRef]

13. Kveiborg, M.; Fröhlich, C.; Albrechtsen, R.; Tischler, V.; Dietrich, N.; Holck, P.; Kronqvist, P.; Rank, F.; Mercurio, A.M.; Wewer, U.M. A role for ADAM12 in breast tumor progression and stromal cell apoptosis. Cancer Res. 2005, 65, 4754-4761. [CrossRef]

14. Nariţa, D.; Anghel, A.; Seclaman, E.; Ilina, R.; Cireap, N.; Ursoniu, S. Molecular profiling of ADAM12 gene in breast cancers. Rom. J. Morphol. Embryol. = Rev. Roum. De Morphol. Embryol. 2010, 51, 669-676.

15. Pories, S.E.; Zurakowski, D.; Roy, R.; Lamb, C.C.; Raza, S.; Exarhopoulos, A.; Scheib, R.G.; Schumer, S.; Lenahan, C.; Borges, V.; et al. Urinary metalloproteinases: Noninvasive biomarkers for breast cancer risk assessment. Cancer Epidemiol. Biomark. Prev. 2008, 17, 1034-1042. [CrossRef]

16. Fröhlich, C.; Nehammer, C.; Albrechtsen, R.; Kronqvist, P.; Kveiborg, M.; Sehara-Fujisawa, A.; Mercurio, A.M.; Wewer, U.M. ADAM12 produced by tumor cells rather than stromal cells accelerates breast tumor progression. Mol. Cancer Res. 2011, 9, 1449-1461. [CrossRef]

17. Roy, R.; Rodig, S.; Bielenberg, D.; Zurakowski, D.; Moses, M.A. ADAM12 transmembrane and secreted isoforms promote breast tumor growth: A distinct role for ADAM12-S protein in tumor metastasis. J. Biol. Chem. 2011, 286, 20758-20768. [CrossRef]

18. Roy, R.; Wewer, U.M.; Zurakowski, D.; Pories, S.E.; Moses, M.A. ADAM 12 cleaves extracellular matrix proteins and correlates with cancer status and stage. J. Biol. Chem. 2004, 279, 51323-51330. [CrossRef]

19. Shao, S.; Li, Z.; Gao, W.; Yu, G.; Liu, D.; Pan, F. ADAM-12 as a diagnostic marker for the proliferation, migration and invasion in patients with small cell lung cancer. PLoS ONE 2014, 9, e85936. [CrossRef] 
20. Fröhlich, C.; Albrechtsen, R.; Dyrskjøt, L.; Rudkjaer, L.; Ørntoft, T.F.; Wewer, U.M. Molecular profiling of ADAM12 in human bladder cancer. Clin. Cancer Res. 2006, 12, 7359-7368. [CrossRef]

21. Peduto, L.; Reuter, V.E.; Sehara-Fujisawa, A.; Shaffer, D.R.; Scher, H.I.; Blobel, C.P. ADAM12 is highly expressed in carcinomaassociated stroma and is required for mouse prostate tumor progression. Oncogene 2006, 25, 5462-5466. [CrossRef]

22. Le Pabic, H.; Bonnier, D.; Wewer, U.M.; Coutand, A.; Musso, O.; Baffet, G.; Clément, B.; Théret, N. ADAM12 in human liver cancers: TGF-beta-regulated expression in stellate cells is associated with matrix remodeling. Hepatology 2003, 37, 1056-1066. [CrossRef]

23. Kodama, T.; Ikeda, E.; Okada, A.; Ohtsuka, T.; Shimoda, M.; Shiomi, T.; Yoshida, K.; Nakada, M.; Ohuchi, E.; Okada, Y. ADAM12 is selectively overexpressed in human glioblastomas and is associated with glioblastoma cell proliferation and shedding of heparin-binding epidermal growth factor. Am. J. Pathol. 2004, 165, 1743-1753. [CrossRef]

24. Georges, S.; Chesneau, J.; Hervouet, S.; Taurelle, J.; Gouin, F.; Redini, F.; Padrines, M.; Heymann, D.; Fortun, Y.; Verrecchia, F. A Disintegrin and Metalloproteinase 12 produced by tumour cells accelerates osteosarcoma tumour progression and associated osteolysis. Eur. J. Cancer 2013, 49, 2253-2263. [CrossRef]

25. Ruff, M.; Leyme, A.; Le Cann, F.; Bonnier, D.; Le Seyec, J.; Chesnel, F.; Fattet, L.; Rimokh, R.; Baffet, G.; Théret, N. The Disintegrin and Metalloprotease ADAM12 Is Associated with TGF- $\beta$-Induced Epithelial to Mesenchymal Transition. PLoS ONE 2015, 10, e0139179. [CrossRef]

26. Mochizuki, S.; Ao, T.; Sugiura, T.; Yonemura, K.; Shiraishi, T.; Kajiwara, Y.; Okamoto, K.; Shinto, E.; Okada, Y.; Ueno, H. Expression and Function of a Disintegrin and Metalloproteinases in Cancer-Associated Fibroblasts of Colorectal Cancer. Digestion 2020, 101, 18-24. [CrossRef]

27. Walkiewicz, K.; Nowakowska-Zajdel, E.; Strzelczyk, J.; Dzięgielewska-Gęsiak, S.; Muc-Wierzgoń, M. Serum levels of ADAM10, ADAM12, ADAM17 AND ADAM28 in colorectal cancer patients. J. Biol. Regul. Homeost. Agents 2017, 31, 929-934.

28. Walkiewicz, K.; Nowakowska-Zajdel, E.; Kozieł, P.; Muc-Wierzgon, M. The role of some ADAM-proteins and activation of the insulin growth factor-related pathway in colorectal cancer. Cent. Eur. J. Immunol. 2018, 43, 109-113. [CrossRef]

29. Brábek, J.; Mierke, C.T.; Rösel, D.; Veselý, P.; Fabry, B. The role of the tissue microenvironment in the regulation of cancer cell motility and invasion. Cell Commun. Signal. 2010, 8, 22. [CrossRef]

30. Brücher, B.L.; Jamall, I.S. Cell-cell communication in the tumor microenvironment, carcinogenesis, and anticancer treatment. Cell. Physiol. Biochem. 2014, 34, 213-243. [CrossRef]

31. Pistritto, G.; Trisciuoglio, D.; Ceci, C.; Garufi, A.; D'Orazi, G. Apoptosis as anticancer mechanism: Function and dysfunction of its modulators and targeted therapeutic strategies. Aging 2016, 8, 603-619. [CrossRef] [PubMed]

32. Diaz-Moralli, S.; Tarrado-Castellarnau, M.; Miranda, A.; Cascante, M. Targeting cell cycle regulation in cancer therapy. Pharmacol. Ther. 2013, 138, 255-271. [CrossRef] [PubMed]

33. Narayanankutty, A. PI3K/Akt/mTOR Pathway as a Therapeutic Target for Colorectal Cancer: A Review of Preclinical and Clinical Evidence. Curr. Drug Targets 2019, 20, 1217-1226. [CrossRef] [PubMed]

34. Kotelevets, L.; Scott, M.G.H.; Chastre, E. Targeting PTEN in Colorectal Cancers. Adv. Exp. Med. Biol. 2018, 1110, 55-73. [CrossRef] [PubMed]

35. Roy, R.; Moses, M.A. ADAM12 induces estrogen-independence in breast cancer cells. Breast Cancer Res. Treat. 2012, 131, 731-741. [CrossRef] [PubMed]

36. Wang, X.; Wang, Y.; Gu, J.; Zhou, D.; He, Z.; Wang, X.; Ferrone, S. ADAM12-L confers acquired 5-fluorouracil resistance in breast cancer cells. Sci. Rep. 2017, 7, 9687. [CrossRef] [PubMed]

37. Ray, A.; Dhar, S.; Ray, B.K. Transforming growth factor-beta1-mediated activation of NF- $\mathrm{kB}$ contributes to enhanced ADAM-12 expression in mammary carcinoma cells. Mol. Cancer Res. 2010, 8, 1261-1270. [CrossRef]

38. Oliveira, R.C.; Abrantes, A.M.; Tralhão, J.G.; Botelho, M.F. The role of mouse models in colorectal cancer research-The need and the importance of the orthotopic models. Anim. Model. Exp. Med. 2020, 3, 1-8. [CrossRef] 